\title{
Intellectual Irrigation Management in Mining Frozen Farming in Azerbaijan
}

\author{
RAE ZH Aliyev* \\ Institute of Soil Science and Agrochemistry of NAS of Azerbaijan, Azerbaijan
}

Received: 制August 30, 2018; Published: 制 September 20, 2018

*Corresponding author: Rae ZH Aliyev, Institute of Soil Science and Agrochemistry of NAS of Azerbaijan, Azerbaijan

\begin{abstract}
This article examines the current state of soil and water resources, farmland t.ch.i Azerbaijan Republic, the problem of progressive water and wind soil degradation, the need for the organization of agriculture, taking into account the introduction of automated control systems for irrigation using water saving technology and hardware equipment in it, the study of the characteristics and analysis of experience implementing measures to stabilize ecological and drainage system of agriculture in conditions of insufficient moisture areas in the country , as well as basic aspects of development of environmental reclamation approach balanced, rational use of a particular system of crop rotation and crop taking into account the requirements of economic development and environmental management.
\end{abstract}

Keywords: Irrigation; Technology; Degradation; Automated Management of low Intensity Zones; Agriculture

\section{Introduction}

The main directions of economic and social development of the Republic is the characteristic intensify agricultural production. A powerful tool for the intensification of agricultural production in the face of his specialization is irrigation. In areas of insufficient moistening (especially typical for mountainous areas) irrigation is one of the decisive factors of the cultivation of high and stable yields of agricultural crops. The purpose of the study: For this purpose, requires the development of new technical solutions and the introduction of automated systems of low irrigation of crops eligible for Ecology and environment Wednesday to improve their environmental condition of irrigated lands, reduce water consumption per unit products and increase the productivity of those or other crops on irrigated field.

\section{Research Methods and Moves the Discussion}

Irrigated soil in Azerbaijan covers 1.45 thousand hectares. It is believed that factors directly affecting the fascination with crop yields and productivity in this area per hectare of arable land and agricultural land at minimal cost, labor and funds also apply automation application. Automated irrigation increases the effectiveness of all factors intensifying: Chemistry, integrated mechanization, intensive technology upgrade, etc. It allows you to create a large zone of guaranteed crop production. objects of Study: The object of the study is to explore and create the correct methods for regulating water use and supply of plants by means of irrigation in regardless of weather conditions. To this end, we have developed and introduced into production design systems of automated management systems for irrigation of low- Micro-tailings of self-oscillating action, successfully passing the resource tested test on vydelochnyh soils under Orchard, Lip Hachmasskoj area on the foothills of the Mountain above level at an altitude of 600 meters sea with sloping terrain 0.02 . (see the concept of impulse systems rain avtokolebatelnogo actions with automated controls Figure1. Construction and functional description of the CMO AY so for operational control of the weather conditions in the region needed to meet the challenges of planning and operational irrigation management crop fields at the local gidrometeopunkte are set measurement sensors with probes for telemetric measurement taking the readings the main parameters:

a) Wind speed-V analog signal (Titus) with period recording of parameter values in the cycle of 30 minutes.

b) Air temperature-tv, analog signal (Titus) with period recording of parameter values in the cycle $30 \mathrm{~min}$.

c) Air humidity-Wb, analog signal (Titus) with period recording of parameter values in the cycle of 30 minutes. 


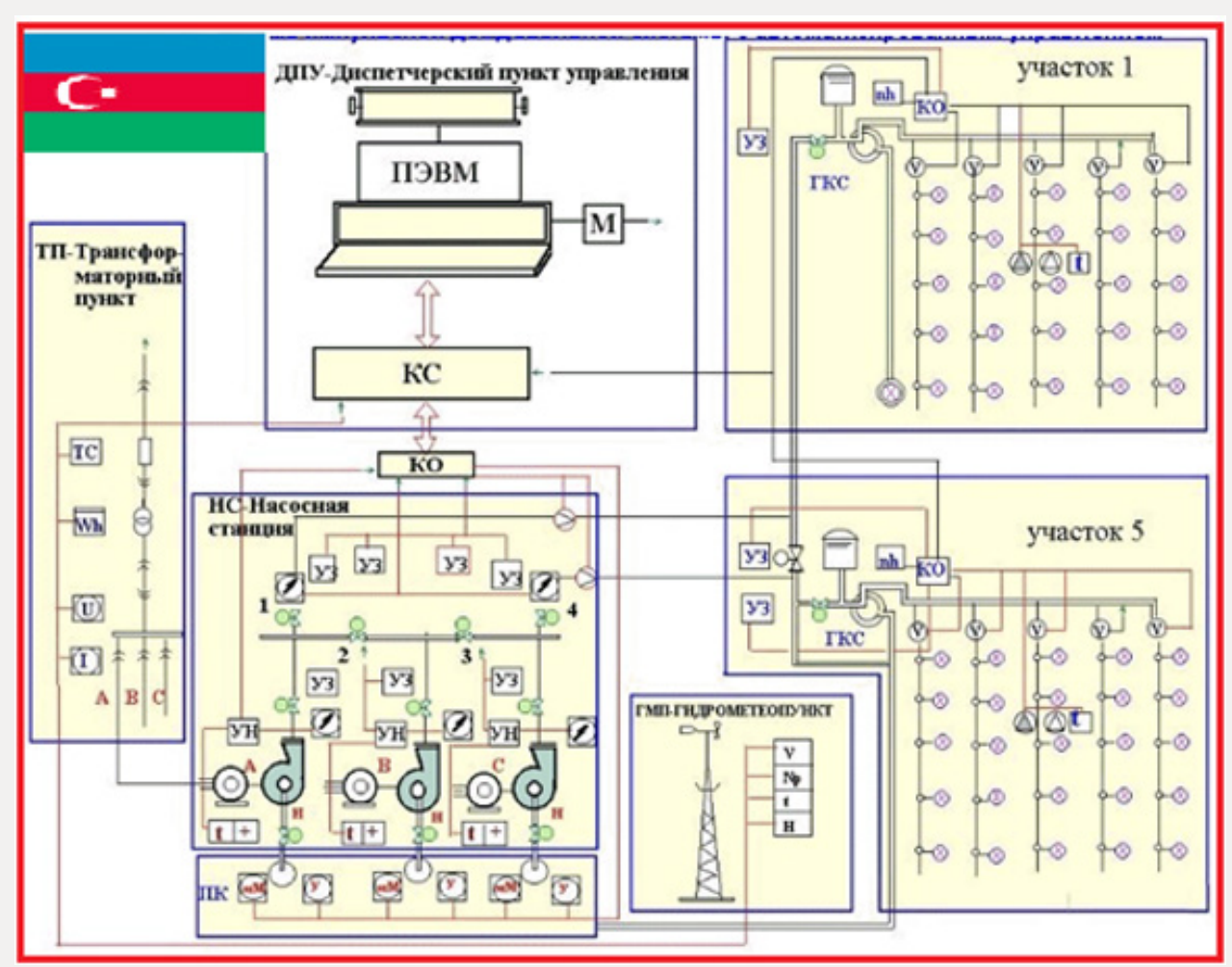

Figure 1: schematic diagram of impulse systems rain avtokolebatelnogo actions with automated controls.

The reading parameter values in the telemetric heskom code is done smart object controller (to) established in paragraph transformer via a radio channel which communicates with sensorsconverters.

Ko otschitannye telemetry signals codes undergo preliminary processing, homogenization and written to main memory, which stores prior to their taking the readings the communications controller (CC) that is installed in the premises of the operational control technology process (ASMO)-operator. For monitoring and control of electricity supply facilities and power consumption accounting to ASMO transform point (TP) (see structural concept of APCS for irrigation) installed transmitters:

i. $\quad$ voltage measuring input) in TP-U (analog signal (Titus)

ii. measurement load consumers-I U (analog signal (Titus)

iii. electricity metering)-Wh (discrete signal integrated-TII

iv. control switch settings (enable-disable consumers)-SS (discrete signal position $\mathrm{SHH}$ ).

Report parameter values in the telemetricheskom code is performed by intelligent object controller (KO) of local wire and after their initial processing and averaging is written into RAM. For monitoring and control technological process of abstraction, clarifiers (wastewater treatment plant) and pumping stations (devices increase the water pressure in the pipes) installed transmitters listed in structurally-functional schema: a. water turbidity in the ponds-m (analog signal loop to read Titus, $30 \mathrm{~min}$ )

b. water level in chambers-ponds-n (analog signal TITUS, read in a loop $30 \mathrm{~min}$ ); in water pressure-r installed on discharge pumps, modular and distribution reservoirs (analog signal TITUS, read in a loop $30 \mathrm{~min}$ )

c. load dimensions electric motors-I (analog signal TITUS, read in a loop $30 \mathrm{~min}$ )

d. provisions of valves-PZ (discrete signal SHH, readable in cycle 1)

e. power switches) Regulations-VP (discrete signal SHH, readable in cycle 1 )

f. alarms-AU (discrete signal TCA, readable in cycle 1 with priority)

g. water metering pumps and supplied in the distribution pipeline-Q (integrated signal TII, processed in the cycle of 1:00).

Soil monitoring and process control of irrigation is carried out according to the specific fields of irrigation based on measurements of the agrophysical and technological parameter sensorsconverters:

I. soil moisture VLP-(analog signal TITUS with a $30 \mathrm{~min}$ cycle) 
II. evaporation from soil surfaces-Exec (analog signal TITUS with a 30 min cycle);

III. soil temperature) $\mathrm{t}^{\circ}$-(analog signal TITUS with a $30 \mathrm{~min}$ cycle)

IV. water consumption irrigation on distribution pipeline plot-Q-(integrated signal with a 30 min cycle)

V. inclusion of the GKS discrete signal readable in a cycle of $30 \mathrm{~s}$

VI. position switching valves (discrete signal read SHH 30 c).

VII. Report telemetricheskom signal code is performed by intelligent object field radio communications controller and after their initial processing and averaging processor is written into RAM.

\section{Enter Operational Data into the Computer and the Formation of a Database (ODB)}

Recorded in the memory controller objects (to) data are programmatically by radio and wire communications controller (CC) connected to your computer Tower (PD) (see circuit diagram system intensity of irrigation and automated controls), according to the specified rules and written in his memory in the structure of the telemetry files (see information provision). Computer exchange programs plays the data from RAM to the COP, transcode them and writes into the database from which displays them in real time on the display mnemoshemah, and after linearized and averaging the data on their codes programmatically are recorded in the cumulative base structure which provides information, and this generates a data bank complex tasks ASMO [1-3].

\section{Information Flows of the Automated System of Low level (ASMO)}

Before writing to the Bank data stream measurement data analyzed by specified algorithms and when the results of the analysis, with deviations from the values specified in the rules of the installations is operational control (OBU) process. Operating base control programmatically at the specified in the rules of the cycle is counted by the management module on technology directions and if there are deviations in the data records for this activity generates a control signal to the appropriate the executive body.

Organization of the Collection and Transmission of Data on the Internet Channels

\section{Conditions for Organization of Data Exchange}

A. Data Interchange on The Work of the System of Irrigation is Carried Out Via the Internet: To do this, you must connect through a computer modem to the telephone network and earn the right to Internet access through an
Internet service provider. This requirement applies to each Subscriber. If these conditions are met, the computer ' The Center can communicate with computers on the sections of the irrigation districts of Azerbaijan and other States.

B. is the site irrigation system, where visitors will see: the latest system state data, interactive pages, created by PHP technology, rapid exchange of data and messages in real time?

C. Using Skype 3 users can talk on the phone and when using cameras to see each other, and when streaming video programs-view the status of the site. When measurements of parameters, it is necessary to take into account the dispersion of available measured values. The value of the parameter, which can be taken for the actual probability of 0.8 , is determined by the number of repetitions of measurements is defined by the formula:

$$
\begin{gathered}
\left.\mathrm{n} \_08 \mathrm{e}, \mathrm{x}=1.64 * 0.001\left(\mathrm{SIG}_{-}(\mathrm{B})\right) *((\mathrm{~W}(\mathrm{HB}) / 10 * \mathrm{~h}) * 2)\right)+ \\
2.27(1)
\end{gathered}
$$

Where is:

$\mathrm{n}=0.8$

(Tr)-number of retries, the measurements meet the probability 0.8 ;

m-0.8 (tr)-measurement accuracy ( $\mathrm{mm})$

SB-standard error of measurement, \%

b (HB) W (HB)-moisture reserves, $\mathrm{mm}$

When humidity b (HB) in the control layer (h) (a), m.

The Source (start) Measurement of Soil Moisture and the Calculation of the Initial Moisture Reserves in the Soil Wo

\section{General description of the Task}

Original moisture reserves W0 soil in the active layer defined by the formula:

$$
\mathrm{d} \text { WHB = W (tau)-W (HB), (2) }
$$

Where is:

$\mathrm{h}(\mathrm{a})$ is an active soil layer, $\mathrm{m}$ (it is assumed that the active layer of the soil is divided into layers of $0.20 \mathrm{~m}-0.30), \gamma$ is the average density of soil layer, $\mathrm{t} / \mathrm{m}^{3}$ entry in program code gamma_sr, $\beta \tau$-soil moisture at field station in $\%$ to mass of dry soil in the program code recording the moment (Veta tau). For automated definition starting soil moisture reserves come from the fact that the value (Veta_tau) is defined $\beta \tau$ measure humidity, it is installed on a stretch of fields on n0, 8 (tr) measurements (write in code, n_0 8 ex). The measured 
values are automatically written to the parameter file Data Par. dbf data bank on $\mathrm{N}_{\text {_ }}$ code element parameter belongs (see. (c) special section ' Data ware $\gg$ ) [3,4]. To specify the conditions for the calculation of the value of the conditionally required variables are written in the job (see. ZADANIE_3 information). Defining the value of starting (the original) soil moisture deficit is determined programmatically moisture reserves and necessary rules. Results of solution of the problem is written to the output document DOC_3 and plotted on the graph.

\section{Description of the Algorithm in Accordance with the Task of Determining Soil Moisture and Moisture Reserves on a Plot of Field Irrigation (see information provision 'ZADANIE_3)}

\section{Searching for Values from the Database (from the Section Information Management)}

Parameter values automatically read from a file Data Par. dbf on $\mathrm{N}_{\text {_ }}$ code element parameter belongs; the value of the $\mathrm{N}_{-}$code element is read from the file ELEM. dbf on key: SL_SYST + SSYST + SL_MODYLE + SL_GROUP + SL_VID + SL_ TYPE. Formation of a lookup key for $\mathrm{N}_{-}$code (see instructions to the operator).

a) Select SL_SYST. dbf) from a file system to which the parameter element.

b) From file SL_SSYST. $d$ bf to select subsystem.

c) From a file + SL_MODYLE-module d bf.

d) From the file SL_GROUP. dbf-the group to which an item belongs measured parameter.

e) From the file SL_VID. dbf-element kind of measured parameter.

f) Of the file item type TYPE. dbf SL_measured parameter.

g) NAME is the NAME of the element is entered from the keyboard;

If the elements identified by coupling multiple (see.ZADANIE_3, write Then Each of them is Assigned a Position Number: The item number is appended to the name through the separator [_] (NAME_1 $>$ ). For formed coupling is TLS_X. $d$ bfN_code. From Data Par. dbf to $\mathrm{N}_{\text {_ code }}+\mathrm{Z}$ date and $<$ PARAM $>$ parameter name in ZADANIE_3 (+) programmatically is its ZNACH value for each field. The obtained values of parameters-moisture content at the specified date, or BETA_tau stocks of moisture on the specified date W (tau) for each section of a field are written to the output DOC. 3 see layouts output documents ' Supply of moisture on irrigation fields $\gg$ After identifying the BETA_tau moisture or soil moisture reserve $\mathrm{W}(\mathrm{tau})$ is defined or moisture deficit soil moisture reserve[2-8]. Determination of moisture deficit soil moisture reserves and to stretch the field and if the software is determined by ZADANIE_3) humidity and BETA_tau of Data Par. dbf found its importance, relatively humidity moisture deficit lowest water consumption BETA_ (HB) is $[2,4,6,8]$

$$
\text { dBETA_HB = BETA_(HB)-BETA_tau (3) }
$$

Where is,

BETA_ (HB)- from SF_ Plot. dbf and Con Soil. dbf; BETA_taufrom the 5.2.4.

Moisture deficit values are automatically written to the output DOC. 3 If for ZADANIE_3 is determined by the supply of moisture in soil W (tau) and of DataPar. dbf found its value, reserve moisture deficit moisture while the smallest capacity $\mathrm{dW}(\mathrm{HB})$ is equal to:

$$
\mathrm{DW}(\mathrm{HB})=\mathrm{W}(\mathrm{tau})-\mathrm{W}(\mathrm{HB})(4)
$$

Where is

W (HB)-from SF_Plot. dbf and

Con Soil. dbf; W_tau-from the 5.2.4.

After Identifying Data for Each of the Specified Sites Field is Determined; and average value) BETA_AV humidity and soil moisture reserves generally $\mathrm{W}_{-} \mathrm{AV}$ on the field:

$$
\text { BETA_AV }=1 / \mathrm{n} \Sigma(\text { BETA_tau) (5) }
$$

Where is

$\mathrm{n}$ is the number of balanced plots involved per from ZADANIE _3, 4 entry;

(BETA _ tau) i -soil moisture is relatively dry soil from 5.2. for each plot.

if defined (W_tau), the average soil moisture reserves the entire field

$$
\text { dBETA_AV }=1 / \mathrm{n} * \Sigma(\text { dBETA_tau) I (6) }
$$

the average value stock deficit soil moisture fields:

$$
\mathrm{dW}_{-} \mathrm{AV}=1 / \mathrm{n} \Sigma\left(\mathrm{dW} \mathrm{AW}_{-} \mathrm{I}(7)\right.
$$

Calculated values in clause 5.2.4. are automatically written to the string $<$ averaging field ....... $>$.

i. Defined e in items 4.5 and 6 DOC. 3 bar chart displays the parameter values 'supply of moisture on the field irrigation $\gg$

ii. after seeing the DOC. 3 prompted $<$ Will solve the problem for other fields on this date $>$. $<$ а $>>,<$ Нет $>$. When you type $<$ Да $><$ message, type the name of the field and economy in ZADANIE_3 > ZADANIE and displayed for data entry.

If the database parameter value specified in ZADANIE_3, it displays an $<$ Value specified in the ZADANIE parameters in the database are missing. Will measure these parameters? $<$ Да $>,<$ Нет $>$. 
If $<$ Да $>$ then go to 5.2.1. If $<$ Нет $>$, then the solution of the problem of consummated and exit the menu. Before starting measurements determines the number of dimensions at each site provides the probability computed value not less than 0.8 at minimum cost of labour on measuring $\mathrm{n} \_0$, 8Ex:

$$
\text { n_0, 8Ex: } \left.\left.=1,64 * 0.001\left(\mathrm{SIG}_{-} \mathrm{B}\right) *(\mathrm{~W}(\mathrm{HB}) / 10 * \mathrm{~h}) * 2\right)\right)+2.27
$$

Where is:

SIG_B-set the value of the standard error in percent; Beta (HB)from ZADANIE_3; -W (HB)-supply of moisture in the soil, in mm when humidity BETA(HB) of the SF_ Plot. dbf; -h is the depth of the soil layer ( $\mathrm{mm}$ ), which should be dimension. Perform $\mathrm{n}_{-} 0$, 8Ex measurements specified ZADANIE_3 parameter, row 2 on each site and write to Data Par. dbf to $\mathrm{N}_{-}$code, $\mathrm{Z}$ date, $\mathrm{Z}$ time. Calculate the mean value of the measurements of (make a selection from Data Par. dbf to $N_{-}$code $+\mathrm{Z}$ date. Average soil moisture reserve $\mathrm{W}_{-} \mathrm{AV}$ is equal to:

$$
\mathrm{W} \_A V=1 / \mathrm{n} \_0,8 \mathrm{Ex} * \Sigma\left(\mathrm{W} \_0,8 \mathrm{Ex}\right) \mathrm{i}(\mathrm{mm})(9)
$$

Where is

W _ $0.8 \mathrm{Ex}$-the value of the stock of moisture each dimension selected in item 4.2.6 (If measured soil moisture BETA_0, 8Ex, the average humidity BETA_AV as well:

$$
\text { BETA_AV }=1 / \mathrm{n}_{-} 0,8 \mathrm{Ex} * \Sigma(\text { BETA_0, } 8) \text { i }(\%)(10)
$$

Where is

BETA_0, 8 Ex-the value soil moisture for each measurement computed values to assign: a) $\quad \mathrm{W} \_\mathrm{AV}:=\mathrm{W}(\mathrm{tau})$;

b) VETA_AV: = BETA_tau and write to output DOC. 3 as in 5.2.1 and 5.2.3 as; 5.2.4.

Filled DOC. 3 is written to the folder that you want to send through the channels of the Internet. Programmed codes are shown in a separate annex.

\section{Conclusion}

The study identified possible operational solving complex problems of an operational definition of soil-conservation settings.

\section{References}

1. B H Aliev, Aliev Z H (2001) Zoning of the Territory of Azerbaijan Republic on Choosing Advanced Irrigation Techniques. /Monograph, Publishing house Ziya. Baku, pp.297.

2. BH Aliev, Aliev ZH (2003) Irrigated Agriculture in the Mountain and Foothill Regions of Azerbaijan. Monograph Publishing house, Naji Zia EPG Ltd, Baku, pp. 330.

3. Aliev B H, Aliev ZH (1999) Techniques and Technology Few Intensive Irrigations in Condition of the Mountain Region of Azerbaijan. Publishers, Elm, Baku, pp. 220.

4. Aliev ZH (2007) The premises about the most important problem of the agriculture in water resource provision mountain and foothill regions of Azerbaijan, //j. AAS, 1-3, Baku, pp. 179-182.

5. Aliev ZH (1999) The premises of the decision of the problems moisture provides agriculture cultures production in mountain and foothill region of Azerbaijan. The works of SRI Erosions and Irrigations, Baku pp. 125129.

6. Mezhdunarodny (2002) Center C/X Research in the dry in the Dry Areas (ICARDA) Irrigation regime and monitoring equipment. Edited $\mathrm{U}$ Umarova, Karimov, Taraz, IC AQUA, pp.128.

7. RB Nosenko (1981) Irrigation in the mountains. Publishing House, Kolos, Moscow pp.143.

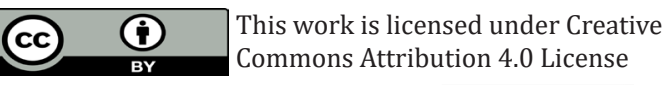

To Submit Your Article Click Here:

Submit Article

DOI: 10.32474/OAJESS.2018.01.000113

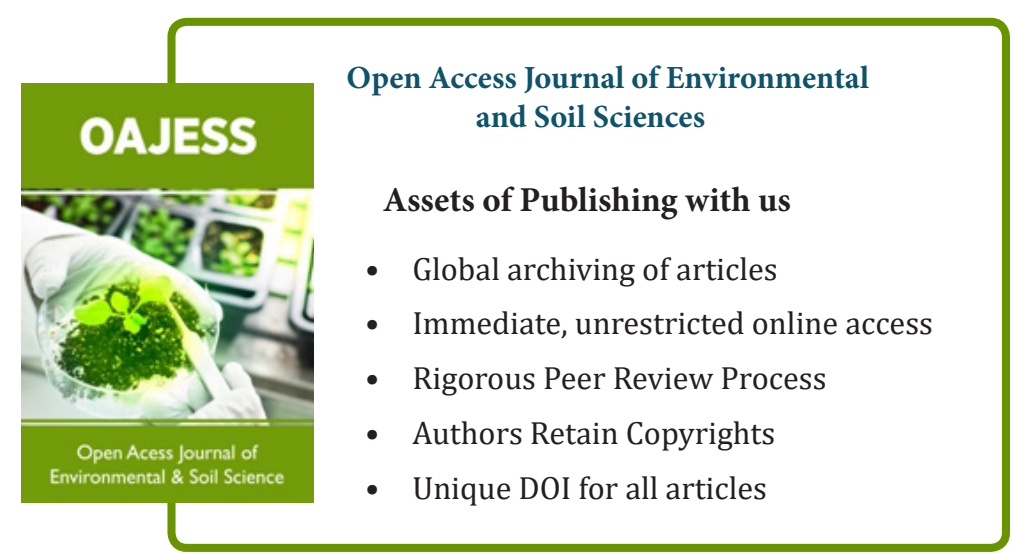

